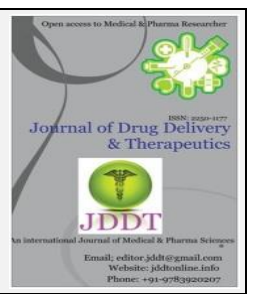

Open Access

Research Article

\title{
Nebulized Glycopyrronium and Formoterol, Budesonide Aerosol Aerodynamic Assessment with Vibrating Mesh and Compressor Air Nebulizer: Anderson Cascade Impactor Study
}

\author{
Menon MD1*, Naik Isha V1, Rajawat G1', Nagarsenker MS'1, Krishnaprasad K² \\ 1 Department of Pharmaceutics, Bombay College of Pharmacy, Kalina, Mumbai, India \\ 2 Medical Services, Glenmark Pharmaceuticals Ltd, Mumbai, India
}

\begin{abstract}
Vibrating mesh nebulizers (VMN) demonstrate improved efficiency for delivery of inhaled aerosol solutions or suspensions as compared to compressor devices. The added advantages of compactness, portability and functioning as noise-free device makes them of incremental value in Home or Ambulatory settings while managing Severe Obstructive airway disease or delivery of maintenance medications in these cases. This further circumvents the need for multiple devices thereby further improving patient compliance and convenience while delivering acute or maintenance formulations including Glycopyrronium (GLY) and Formoterol (FRM)/Budesonide(BUD) nebulizing solution formulations. To further assess the clinical role and feasibility of FRM-BUD formulation delivery kinetics with or without GLY nebulizing solution through VMN and jet nebulizers for In- \& outpatient settings, 2 comparative in-vitro lung deposition studies were carried out utilizing Anderson Cascade impactor at $30 \mathrm{~L} / \mathrm{min}$; with deposited drug estimated by HPLC. Post-hoc analyses with p<0.05 were considered statistically significant for intergroup differences on FRM/BUD and GLY delivered through VMN or Compressor devices. The calculated mean fine particle dose for FRM \& BUD delivered by VMN or jet nebulizer showed no statistical difference. However the mean fine particle fraction for BUD deliv ered by VMN was significantly better compared to jet nebulizer. The Residual volume at 10 mins was significantly higher with jet nebulizer. The optimal Aerodynamic Particle Size Distribution (APSD) for GLY nebulizing solution admixture with FRM/BUD suspension delivered through VMN and Jet nebulizer offers a clinically relevant strategy for High risk COPD cases in Acute or Home settings.
\end{abstract}

Keywords: Anderson cascade impactor, Fine particle fraction, Fine particle dose, Glycopyrronium, Formoterol/Budesonide, Nebulizing formulation, Vibrating Mesh nebulizer

Article Info: Received 09 Aug 2019; Review Completed 03 Sep 2019; Accepted 23 Sep 2019; Available online 15 Nov 2019

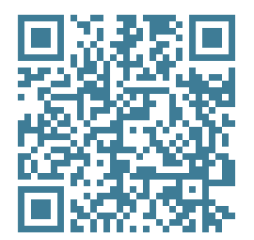

Cite this article as:

Menon MD, Naik IV, Rajawat G, Nagarsenker MS, Krishnaprasad K, Nebulized Glycopyrronium and Formoterol, Budesonide Aerosol Aerodynamic Assessment with Vibrating Mesh and Compressor Air Nebulizer: Anderson Cascade Impactor Study, Journal of Drug Delivery and Therapeutics. 2019; 9(6):79-82 http://dx.doi.org/10.22270/jddt.v9i6.3465

*Address for Correspondence:

Dr. (Prof) Mala D Menon, Prof \& HOD, Department of Pharmaceutics, Bombay College of Pharmacy, Kalina, Mumbai, India

\section{INTRODUCTION}

India has growing burden of chronic respiratory diseases including Bronchial asthma, asthma-COPD overlap (ACO) and COPD that are an important contributor towards deaths and disability adjusted life years (DALYs).

The contribution of chronic respiratory diseases to the total DALYs in India increased from $4 \cdot 5 \pm 0.4 \%$ in 1990 to $6 \cdot 4 \pm 0.6 \%$ in 2016. Of the total DALYs due to chronic respiratory diseases in India, COPD and asthma account for $75 \cdot 6 \%$ and $20 \cdot 0 \%$ respectively 1 .

Recent studies of peak inspiratory flow after recovery from an acute exacerbation found that $19 \%-52 \%$ of COPD patients had insufficient peak inspiratory flow for effective DPI use, and those patients were more likely to be older and have more severe disease ${ }^{2}$. In most of these cases (ie. GOLD D), the administration of ICS/LABA and LAMA remains a clinical challenge with the conventional devices with almost onethird of the post-discharge cases having low peak inspiratory flow rate (PIFR) of $\approx 30 \% \mathrm{l} / \mathrm{min}$ following a severe exacerbation. However in case of a differential diagnosis involving clinical symptomatology of ACO, baseline therapy of ICS/LABA with LAMA is again recommended 3 . In either of these cases, education, adherence and review of patient inhalation technique in the post-discharge phase remains critical for optimizing health outcomes especially with conventional devices.

A systematic review found that $45 \%$ of pMDI users had suboptimal hand-breath coordination for optimal drug delivery. Coordination limitations can be addressed by the 
use of holding chambers or spacers; however, errors in handling, execution, and breath holding technique are still common ${ }^{4,5}$.

The mainstay of treatment involves delivery of rescue and maintenance therapies through a compressor air (jet) nebuliser along with short course therapy with steroids and antibiotics. Compressor air nebulizers commonly used in hospitals require a compressor or pressurized gas source to operate, and tend to be inefficient, leaving up to $1.4 \mathrm{~mL}$ of medication in the reservoir at end of dose. To overcome the limitations of compressor air nebulizers, several new nebulizer technologies, such as active vibrating mesh nebulizers (VMN), have been developed. The VMN is electronically operated, requiring no gas to generate aerosol, with greater efficiency associated with low residual drug volume at end of nebulization $(<0.1 \mathrm{~mL})^{6-8}$. while delivering rescue or maintenance nebulizing solutions including ICS/LABA and/or anticholinergics.

Glycopyrronium and Formoterol/Budesonide nebulizing formulations have been available as Maintenance therapy for the management of obstructive airway diseases and related phenotypes including $\mathrm{ACO}^{9}$. Combination of these drug solutions or suspensions in the nebulizer for simultaneous nebulization remains a pertinent strategy in clinical practice ${ }^{10}$. However, little information is available on the compatibility of drugs when admixed for the effect on particle size distribution and aerosol output

To further assess the clinical role and feasibility of Formoterol/ Budesonide formulation delivery kinetics with and without combination with Glycopyrronium formulation through VMN and Compressor air nebulizers for In- \& outpatient settings, two comparative in vitro lung deposition studies were carried out utilizing Anderson Cascade impactor

\section{MATERIAL AND METHODS}

The in vitro Lung deposition studies were carried out using Anderson Cascade impactor (ACI) at $30 \mathrm{~L} / \mathrm{min}$ using Nebulizing formulations of Glycopyrronium $(25 \mathrm{mcg} / 2 \mathrm{ml})$ and Formoterol/Budesonide $(20 / 500 \mathrm{mcg})$ provided by Glenmark Pharmaceuticals Ltd.

The ACI study was carried out for the assessment of the aerodynamic properties of the above mentioned products for nebulization using both the nebulizers, i.e. jet and the vibrating mesh types. Inspiratory flow rate of $30 \mathrm{~L} / \mathrm{min}$ was used as per manufacturer's specifications (Copley Scientific).ACI was assembled with glass fiber filter and stages (S-0, S1, S2, S3, S4, S5, S6, S7).
Formoterol/Budesonide smartule $20 / 500 \mathrm{mcg} / 2 \mathrm{ml}$ for Study I and Formoterol/Budesonide smartule 20/500 mcg/ $2 \mathrm{ml} \&$ Glycopyrronium nebulizing solution $25 \mathrm{mcg} / 2 \mathrm{ml}$ for Study II were opened and the contents placed in nebulizer medication chamber. For Compressor air nebulizer, the smartule content were diluted with distilled water. The length of the time interval for nebulization for each device was decided based on the time required for the delivery of volume of MilliQ water equivalent to the volume of contents of the smartule and the diluent for the corresponding nebulizer device, ensuring the sufficient amount of drug to be delivered in the ACI assembly for the purpose of quantification. Apparatus was dismantled and each stage and filter were carefully washed with suitable solvent (diluentMethanol AR: MilliQ water in 60:40 ratio) and washings collected into a beaker (Volume of the solvent used: $25 \mathrm{ml}$ for Device and induction port washings and $10 \mathrm{ml}$ for remaining stages). Active substance at each stage (deposition) was determined by using developed reverse phase gradient HPLC method of analysis.

The recovered active substance deposition from each stage of the cascade impactor was processed in the CITDAS software provided by Copley Scientific Ltd. UK. The characteristics of the aerosol were determined and assessed using several parameters including fine particle fraction (FPF), MMAD, and fine particle dose (FPD). The definitions included FPF: Fraction of the aerosol that is in a size range with the potential of the fine particle $(<5 \mu)$ dose divided by the total delivered dose; MMAD: Diameter of drug particles at which $50 \%$ of particles by mass is larger and $50 \%$ are smaller; FPD is the quantity of drug with fine particle size and related to drug deposition in the lung,[4-6]

\section{RESULTS}

In vitro Lung deposition was characterized by FPD, FPF, MMAD, Nebulization time \& Residual volume for Formoterol/Budesonide \& Glycopyrronium nebulizing suspension delivered by VMN or Compressor air nebulizer in both the studies. (Tables 1,2)

In Study I, the calculated mean FPD for Formoterol \& Budesonide delivered by VMN or Compressor air nebulizer showed no statistical difference $(\mathrm{p}=0.19$ \& $\mathrm{p}=0.15$ respectively). Similarly, the mean FPF for Formoterol was again comparable in both the arms ( $p=N S)$ with incremental impact on Budesonide delivery by VMN that was significantly better compared to Compressor air nebulizer $(p=0.04)$. The Residual volume at 10 mins was significantly higher with Compressor air nebulizer $(0.5 \mathrm{ml})$.

Table 1: Study I, in vitro Lung deposition study results using ACI with VMN \& Compressor air nebulizer for Formoterol/ Budesonide nebulizing suspension

\begin{tabular}{|l|l|c|c|c|c|}
\hline \multirow{2}{*}{$\begin{array}{l}\text { Sr. } \\
\text { no. }\end{array}$} & Parameter & \multicolumn{2}{c|}{ Vibrating Mesh Nebulizer } & \multicolumn{2}{c|}{ Compressor Air Nebulizer } \\
\cline { 3 - 6 } & & Formoterol & Budesonide & Formoterol & Budesonide \\
\hline 1 & FPD & $11.9 \pm 3.0^{*}$ & $183.2 \pm 63^{*}$ & $7.3 \pm 0.2$ & $71.1 \pm 11.2$ \\
\hline 2 & FPF & $68.4 \pm 8.6^{*}$ & $62.2 \pm 5.03 \#$ & $59.7 \pm 1.6$ & $45.5 \pm 2.2$ \\
\hline 3 & MMAD & $3.7 \pm 0.5^{*}$ & $4.3 \pm 0.2 \#$ & $4.5 \pm 0.1$ & $5 \pm 0.1$ \\
\hline 4 & Residual Volume & \multicolumn{2}{|c|}{ Negligible } & \multicolumn{2}{c|}{$0.5 \mathrm{ml}$} \\
\hline
\end{tabular}

* $\mathrm{p}=\mathrm{NS}$ vs Compressor air nebulizer; $\# \mathrm{p}<0.05$ vs. Compressor air nebulizer.

FPD: Fine Particulate Dose $(<5 \mu) ; \quad$ FPF: Fine Particle Fraction $(\%$ Drug $<5 \mu) ; \quad$ MMAD: Median mass aerodynamic diameter

The second study (Study II) explored for the first time the clinical feasibility of Glycopyrronium solution admixture with Formoterol/Budesonide formulation assessing the APSD or delivery kinetics in real world outpatient settings of ISSN: 2250-1177
India. In case of formoterol Fumarate, glycopyrronium and budesonide there is no statistically significant difference observed in MMAD, FPD, and FPF between two nebulizer devices. 
Table 2: Study II, In vitro Lung deposition study results using ACI with VMN \& Compressor air nebulizer for Formoterol/ Budesonide nebulizing suspension in combination with Glycopyrronium nebulizing solution

\begin{tabular}{|c|c|c|c|c|c|c|c|}
\hline \multirow{2}{*}{$\begin{array}{l}\text { S. } \\
\text { N. }\end{array}$} & \multirow[t]{2}{*}{ Parameter } & \multicolumn{3}{|c|}{ Vibrating Mesh Nebulizer } & \multicolumn{3}{|c|}{ Compressor Air Nebulizer } \\
\hline & & Formoterol & Budesonide & $\begin{array}{c}\text { Glyco- } \\
\text { pyrronium }\end{array}$ & Formoterol & Budesonide & $\begin{array}{c}\text { Glyco- } \\
\text { pyrronium }\end{array}$ \\
\hline 1 & FPD & $10.59 \pm 4.08^{*}$ & $139.21 \pm 67.58^{*}$ & $15.22 \pm 7.34^{*}$ & $7.06 \pm 2.52$ & $116.14 \pm 65.65$ & $14.99 \pm 9.03$ \\
\hline 2 & FPF & $48.88 \pm 6.74^{*}$ & $43.77 \pm 13.16^{*}$ & $54.44 \pm 10.26^{*}$ & $45.34 \pm 14.12$ & $42.94 \pm 6.06$ & $57.19 \pm 14.37$ \\
\hline 3 & MMAD & $4.97 \pm 0.67^{*}$ & $5.1 \pm 0.75^{*}$ & $4.44 \pm 1.06^{*}$ & $5.1 \pm 0.66$ & $5.2 \pm 0.26$ & $4.4 \pm 1.22$ \\
\hline 4 & $\begin{array}{l}\text { Residual } \\
\text { Volume }\end{array}$ & \multicolumn{3}{|c|}{ Negligible } & \multicolumn{3}{|c|}{$0.12 \mathrm{ml}$} \\
\hline
\end{tabular}

${ }^{*} \mathrm{p}=\mathrm{NS}$ vs Compressor air nebulizer; \#p<0.05 vs. Compressor air nebulizer

FPD: Fine Particulate Dose $(<5 \mu) ; \quad$ FPF: Fine Particle Fraction $(\%$ Drug $<5 \mu) ; \quad$ MMAD: Median mass aerodynamic diameter

\section{DISCUSSION}

This is the first study to assess the pharmacokinetic compatibility and delivery kinetics for Formoterol/ Budesonide with or without Glycopyrronium nebulizing formulations when admixed at the same time for delivery with Active vibrating mesh and compressor air nebulizer. The only publications till date by Akapo ${ }^{11}$ and Kamin ${ }^{12}$ suggest the likely compatibility of above formulations as admixture with no further evidence on the clinical impact or in vitro lung deposition or APSD assessments. These results have likely impact on the clinical role of Home nebulization for delivery of Rescue or Maintenance therapies particularly in High risk COPD cases while preventing 30-day readmission or 1-yr mortality that is quite common in such cases 13,14 due to varying reasons including nonadherence or suboptimal utilization of the conventional devices.

In this line Home nebulization with the conventional compressor air nebulizers are often considered cumbersome, bulky, noisy for delivery of rescue and maintenance therapies especially for ambulatory patients. Literature review suggests bacterial contamination of nebulizers used by patients has often been described ${ }^{15}$. Even in most developed countries, an investigation of different components of nebulizer systems used at home showed that $50 \%$ of these components were contaminated ${ }^{16}$. The new generation, handy, portable, noise-free vibrating mesh nebulizers offer minimal intervention with regular hygiene of the medication cup on every use

The results of the current studies with active VMN the mean values for fine particle dose (FPD) and Fine particle fraction (FPF) from APSD testing are well within the specified limits including 85 to $115 \%$ of the emitted dose from the compressor air nebulizer ${ }^{17}$.The results are also comparable to the APSD testing and results for Glycopyrronium nebulizing solution tested for delivery with eFLOW*Closed System nebulizer that is available in the international market 18,19 .

The observed results for FPF $(\geq 50 \%)$ ensures optimal efficiency with active VMN and compressor air nebulizer for delivery of Nebulizing Suspension/s during acute exacerbation or maintenance therapy in stable cases. Negligible residual volume with zero dilution factor further complements the clinical rationality and utility of active VMN for Home nebulization for delivery of rescue or maintenance medications.

The results need to be further evaluated in large pivotal clinical trials to further assess the clinical impact of the dual or triple drug combination aerosol delivery kinetics or lung deposition on clinical endpoints in High risk COPD cases as maintenance therapy. Although both CEN and USP [601] recommend the aerosol characterization for nebulizing formulations with $15 \mathrm{~L} / \mathrm{min}$ flow rate, the results with the current study are incremental in mimicking the real world practice of pMDI or VMN attachment to proximal arm of noninvasive ventilation (NIV) that may hamper the smooth inhalation of the Soft mist generated subsequently for adequate inhalation in such cases on BiPAP or IPAP/EPAP airflow maneuvers ${ }^{20,21}$.

The current study was therefore conducted using ACI at 30 $\mathrm{L} / \mathrm{min}$, (Copley Scientific), patients of AECOPD during acute or post discharge phase of moderate or severe exacerbation 21,22 .

\section{CONCLUSION}

The optimal APSD for Glycopyrronium nebulizing solution admixture with Formoterol/Budesonide suspension delivered through VMN and Compressor air nebulizer offers a clinically relevant strategy for High risk COPD cases in Acute or Home settings

Conflict of interest: The authors declare that there are no conflicts of interest to publish this paper.

Disclosure: The in vitro lung deposition study using Anderson Cascade impactor was supported by Academic grant from Glenmark Pharmaceuticals Ltd, Mumbai, India.

\section{REFERENCES}

1. Salvi S, Kumar GA, Dhaliwal RS, Paulson K, Agrawal A, Koul PA, Mahesh PA, Nair S, Singh V, Aggarwal AN, Christopher DJ, The burden of chronic respiratory diseases and their heterogeneity across the states of India: the Global Burden of Disease Study 1990-2016, The Lancet Global Health, 2018 Dec $1 ; 6(12): \mathrm{e} 1363-74$.

URL:

https://www.sciencedirect.com/science/article/pii/S221410 9X18304091

2. Sanchis J, Gich I, Pedersen S, Team AD, Systematic review of errors in inhaler use: has patient technique improved over time?, Chest, 2016 Aug 1; 150(2):394-406.

URL:

https://www.sciencedirect.com/science/article/pii/S001236 9216475719

3. Loh CH, Peters SP, Lovings TM, Ohar JA, Suboptimal inspiratory flow rates are associated with chronic obstructive pulmonary disease and all-cause readmissions, Annals of the American Thoracic Society, 2017 Aug; 14(8):1305-11. 
URL:

https://www.atsjournals.org/doi/full/10.1513/AnnalsATS.20 1611-9030C

4. Mahler DA, Waterman LA, Gifford AH, Prevalence and COPD phenotype for a suboptimal peak inspiratory flow rate against the simulated resistance of the Diskus $®$ dry powder inhaler, Journal of aerosol medicine and pulmonary drug delivery, 2013 Jun 1; 26(3):174-9.

URL:

https://www.liebertpub.com/doi/abs/10.1089/jamp.2012.09 87

5. Dolovich MB, Dhand R, Aerosol drug delivery: developments in device design and clinical use, The Lancet, 2011 Mar 19; 377(9770):1032-45

URL:

https://www.sciencedirect.com/science/article/pii/S014067 3610609269

6. Dhand R, Nebulizers that use a vibrating mesh or plate with multiple apertures to generate aerosol, Respiratory care, 2002 Dec; 47(12):1406-6.

URL: https://europepmc.org/abstract/med/12467499

7. Waldrep JC, Dhand R, Advanced nebulizer designs employing vibrating mesh/aperture plate technologies for aerosol generation, Current Drug Delivery, 2008 Apr 1; 5(2):114-9.

URL:

https://www.ingentaconnect.com/content/ben/cdd/2008/00 000005/00000002/art00006

8. Krishnaprasad K, Mahashur A, Sagar C, Pophale H, Agrawal G, Das A, Katke P. Glycopyrrolate in High-risk COPD, a Drug utilization surveillance study in India (GOAAL): Post-hoc analyses. Respirology 2018: AP

116https://doi.org/10.1111/resp.13420_116(Accessed on 9th June 2019)

9. Melani AS, Effects on aerosol performance of mixing of either budesonide or beclomethasone dipropionate with albuterol and ipratropium bromide, Respiratory care, 2011 Mar 1;56(3):319-26. URL:

http://rc.rcjournal.com/content/56/3/319.short

10. Akapo S, Gupta J, Martinez E, McCrea C, Ye L, Roach M. Compatibility and Aerosol Characteristic of Formoterol Fumarate Mixed with Other Nebulizing Solutions. Annals of Pharmacotherapy. 2008 Oct; 42(10):1416-24.

URL:

https://journals.sagepub.com/doi/abs/10.1345/aph.11273

11. Kamin W, Schwabe A, Krämer I, Inhalation solutions-which one are allowed to be mixed? Physico-chemical compatibility of drug solutions in nebulizers, Journal of cystic fibrosis, 2006 Dec 1; 5(4):205-13.

URL:

https://www.sciencedirect.com/science/article/pii/S156919 9306000415

12. Jacobs DM, Noyes K, Zhao J, Gibson W, Murphy TF, Sethi S, Ochs-Balcom HM, Early hospital readmissions following an acute exacerbation of COPD in the Nationwide Readmissions Database, Ann Am Thorac Soc, 2018 Apr 3; 15:837-345.

URL: https://www.ncbi.nlm.nih.gov/pubmed/29611719

13. García-Sanz MT, Cánive-Gómez JC, Senín-Rial L, Aboal-Viñas J, Barreiro-García A, López-Val E, González-Barcala FJ, One-year and long-term mortality in patients hospitalized for chronic obstructive pulmonary disease, Journal of thoracic disease, 2017 Mar; 9(3):636
URL:

https://www.ncbi.nlm.nih.gov/pmc/articles/PMC5394058/

14. Barnes KL, Clifford R, Holgate ST, Murphy D, Comber P, Bell E Bacterial contamination of home nebulizer, British medical journal (Clinical research ed.), 1987 Oct 3; 295(6602):812.

URL:

https://www.ncbi.nlm.nih.gov/pmc/articles/PMC1247857/

15. Struycken VH, Tiddens HA, Dzoljic-Danilovic G, Problems in the use, cleaning and maintenance of nebulization equipment in the home situation, Nederlands tijdschrift voor geneeskunde, 1996 Mar; 140(12):654-8.

URL: https://europepmc.org/abstract/med/8668238

16. Lewis D. Rouse T, Singh D, Edge S, Defining the 'Dose' for Dry Powder Inhalers: The Challenge of Correlating In-Vitro Dose Delivery Results with Clinical Efficacy, American Pharmaceutical Review 2017; 20(3), 54-62

URL:

https://www.researchgate.net/profile/Stephen_Edge2/public ation/316826164_Defining_the_\%27Dose\%27_for_Dry_Powde r_Inhalers_The_Challenge_of_Correlating_In-

Vitro_Dose_Delivery_Results_with_Clinical_Efficacy/links/591 31b08aca27200fe4b28e6/Defining-the-Dose-for-Dry-PowderInhalers-The-Challenge-of-Correlating-In-Vitro-DoseDelivery-Results-with-Clinical-Efficacy.pdf

17. Pham S, Ferguson GT, Kerwin E, Goodin T, Wheeler A, Bauer A, In vitro characterization of the eFlow closed system nebulizer with glycopyrrolate inhalation solution, Journal of aerosol medicine and pulmonary drug delivery, 2018 Jun 1 31(3):162-9.

URL:

https://www.liebertpub.com/doi/full/10.1089/jamp.2017.13 84

18. Korukonda K, Dhatrak C, Ankam R, Rajurkar S, Chaudhari S, In Vitro Comparative Assessment and Characterization of Vibrating Mesh Nebulizers with Glycopyrronium Nebulizing Solution: New Generation Impactor Study, Int J Sci Stud, 2019; 7(1):1-3 URL: https://www.ijsssn.com/uploads/2/0/1/5/20153321/17_ijss_apr_oa17__2019.pdf

19. European Committee for Standardization. CEN: EN 13544-1: 2007+A1:2009: Respiratory Therapy Equipment: Nebulizing Systems and Their Components. London: British Standards Institute; 2010

20. USP 31. Aerosols, Nasal Sprays, Metered Dose Inhalers and Dry Powder Inhalers; Chapter 601. USP 31. Uniformity of Dosage Units. Chapter. 905. USP 31. Available from: https://www.usp.org/sites/default/files/usp/document/har monization/gen-method/q0304_pf_ira_32_6_2006.pdf. [Last accessed on 2019 Mar 05]

21. Sharma G, Mahler DA, Mayorga VM, Deering KL, Harshaw Q, Ganapathy V, Prevalence of low peak inspiratory flow rate at discharge in patients hospitalized for COPD exacerbation, Chronic Obstructive Pulmonary Diseases: Journal of the COPD Foundation, 2017;4(3):217.

URL:

https://www.ncbi.nlm.nih.gov/pmc/articles/PMC5556913/

22. Copley M, Pulmonary drug delivery: Technology, regulation and testing, Drug Delivery Technology Oct 2008, 2008 Oct; $8(9)$.

URL:

https://www.copleyscientific.com/files/ww/news/COP\%20J OB\%20055_Pulmonary\%20Drug\%20Delivery\%20DDT\%200c t\%202008.pdf 